\title{
Padrão espacial do emprego formal no Paraná
}

\section{Space standard of formal employment in Paraná}

\author{
Ariana Cericatto da Silva, ${ }^{1}$ \\ Elaine Carvalho de Lima $^{2}$ \\ Érica Priscilla Carvalho de Lima
}

\section{RESUMO}

O trabalho analisa o perfil espacial da localização do emprego formal no estado do Paraná, no período de 2002 e 2011. Para a análise utilizaram-se medidas de localização para o estudo dos setores econômicos entre as mesorregiões, dentre elas elegeu-se o Quociente de Localização e o Coeficiente de Redistribuição, utilizando-se de dados da Relação Anual de Informações Sociais (RAIS) do Ministério do Trabalho e do Emprego (MTE). Os resultados apontaram que a agricultura apresenta alta concentração de emprego formal em quase todas as mesorregiões paranaenses, com exceção da mesorregião Metropolitana de Curitiba. Assim, a agricultura responde por uma importante fonte de emprego e renda no estado do Paraná. Para o setor industrial, observa-se que a Indústria Dinâmica está concentrada, em apenas duas mesorregiões, Metropolitana de Curitiba e Sudeste Paranaense. Já o setor de Comércio apresentou um padrão semelhante no período de análise para quase a totalidade das mesorregiões, exceto: Noroeste Paranaense, Norte Pioneiro Paranaense e Metropolitana de Curitiba.

Palavras chaves: Economia Regional, Economia Paranaense, Análise Regional, Economia Espacial.

\section{ABSTRACT}

The paper analyzes the spatial profile of the location of formal employment in the Paraná State in Brazil, between 2002 and 2011. For the analysis we used the measures of location for analysis of economic sectors between the regions and among them was elected Location Quotient and redistribution coefficient, using data from the Annual Report of Social Information (RAIS) Ministry of Labor and Employment (MTE). The results showed that agriculture presents greater dispersion of formal employment in almost all regions of Paraná State, with the exception of the middle region of Curitiba's city. Thus, agriculture accounts for a major source of employment and income in the state of Paraná. For the industrial sector, it is observed that the Traditional Industry presents greater dispersion between the Paraná regions, while the Non-Traditional Industry and Industry dynamics are more concentrated.

Key-Words: Regional Economy, Parana, Regional Analysis, Spatial Economy.

JEL Classification: J01, R10

\footnotetext{
${ }^{1}$ Docente da UNIOESTE. Mestra em Desenvolvimento Regional e Agronegócio pela Universidade Estadual do Oeste do Paraná - UNIOESTE/Toledo. Graduada em Ciências Econômicas. E-mail: ariana cericatto@hotmail.com

${ }^{2}$ Doutoranda em Economia pela UFU. Mestra em Economia (UFRN). Graduada em Ciências Econômicas (UFRN).e-mal : elainecarvalhoonline@hotmail.com

${ }^{3}$ Docente do Departamento de Economia da UERN. Mestra em Estudos Urbanos e Regionais (UFRN). Graduada em Ciências Econômicas (UFRN). E-mail : ericapcl1@gmail.com
} 


\section{INTRODUÇÃO}

Uma discussão relevante na teoria econômica é a espacialização das atividades e seus fatores explicativos. Desse debate emerge a importância da descentralização da economia em prol de uma melhoria na distribuição das atividades, bem como pela geração de emprego e renda principalmente para cidades menores.

O processo de interiorização da economia paranaense ocorreu a partir dos anos 1970, conferindo uma nova dinâmica locacional ao estado, além de potencializar o desempenho econômico dos municípios envolvidos. Os fatores explicativos dessa interiorização foram o surgimento de uma nova dinâmica na agricultura, a expansão da fronteira agrícola, o adensamento das cidades médias e a constituição dos complexos agroindustriais, em especial nas Regiões Sudeste e Sul, e a ocupação de terras no Centro-Oeste e Norte do país (IPEA, 2001).

$\mathrm{Na}$ década de 1990, ocorreram novas alterações na base produtiva e na organização espacial do Paraná, tais como: fortalecimento das cidades médias, as novas formas de trabalho assalariado, o fortalecimento da agroindústria familiar, a agroindustrialização, a diversificação industrial e a integração do Mercosul. As relações comerciais entre Brasil e países da América do Sul também estimularam uma nova forma de comércio interregional. Esses fatores propiciaram o aumento da participação da indústria de transformação dos estados da Região Sul na economia brasileira, em especial do estado do Paraná (PEREIRA; FERRERA DE LIMA, 2008).

Cabe ressaltar que a década de 1990 foi o período da afirmação da agroindústria de carne e derivados, no Paraná, além da implantação do pólo automotivo na Região Metropolitana de Curitiba. Destacaram-se e consolidaram-se as atividades agroindustriais, relacionadas ao complexo da soja e a produção, abate e industrialização de suínos, aves e bovinos (PIFFER, 1999).

Não obstante, é crucial saber como a nova configuração espacial está relacionada com as atividades produtivas nessas áreas localizadas. Desta forma, o presente estudo parte da problemática de compreender como se configura o padrão espacial do emprego formal das atividades econômicas no estado do Paraná, nos anos de 2002 a 2011.

O objetivo central do artigo é investigar como a estruturação espacial se reproduz na economia do estado tendo como variável chave a distribuição do emprego formal. Este é um indicador importante para verificar o desempenho socioeconômico tendo em vista que rebate no poder aquisitivo da população e a potencialidade do multiplicador na economia, através da geração de renda resultante. Pretende-se contribuir na discussão de como as transformações incorridas na localização das atividades resultam em uma reconfiguração espacial que torna alguns espaços mais dinâmicos que outros.

Este artigo se encontra dividido em seis seções, incluindo a introdução. $\mathrm{Na}$ segunda apresenta-se uma breve revisão dos conceitos de espaço e região. $\mathrm{Na}$ terceira seção é apresentada uma revisão teórica das principais contribuições acerca das teorias do padrão locacional e regional das atividades econômicas. Na quarta seção, apresenta-se a metodologia utilizada, e na seção seguinte os resultados obtidos, reservando ao último item a apresentação de algumas considerações finais. 


\section{REVISÃO DE LITERATURA}

A constatação de que as atividades desempenham funções diferenciadas e complementares dentro de uma determinada região deu origem à análise regional, que procura identificar e justificar a forma das organizações regionais. A análise regional leva em consideração a definição de região e o perfil da polaridade.

A região não tem fronteiras no sentido econômico, pois no desenvolvimento capitalista as trocas ocorrem sem observar as fronteiras regionais, o que faz com que as mudanças de uma região para outra sejam relevantes, por se fazerem sem entraves administrativos. Uma condição de existência da região, como conceito econômico, é a de pertencer a um espaço econômico maior, não sendo necessário que a região tenha uma existência administrativa própria. A delimitação das fronteiras regionais pode obedecer a necessidades políticas, culturais ou administrativas (POLĖSE, 1998).

Não se define região segundo o tamanho ou sua fronteira; supõe-se que a região seja um subsistema do sistema nacional. Porém não é evidente como uma economia nacional possa ser subdividida em regiões. O espaço regional deve, entretanto, ser contíguo e todo o espaço nacional deve ficar contido em uma ou outra região (SOUZA, 1980; LOPES, 2002).

A região é o espaço fora da capital e das metrópoles, ou seja, é o interior. Ela é o lugar de identidade, de tradições, de contiguidade, na qual se fixam agrupamentos humanos. Mesmo assim, esses elementos não são suficientes para manter uma população. A região, para seu pleno desenvolvimento, deve ser capaz de criar empregos, garantir a sustentabilidade dos recursos naturais e as condições de vida da população (FERRERA DE LIMA; EBERHARDT, 2010).

Já na questão da polaridade, as regiões são definidas como áreas de influência polarizadas por uma aglomeração ou um lugar central. O critério de homogeneidade parte do princípio dos traços característicos das regiões, e é por meio de características semelhantes que seu agrupamento é determinado. Já o critério de fronteiras políticas ou administrativas, são traçadas em funções das necessidades de organismos especializados (POLĖSE, 1998).

Cabe ressaltar que o princípio da polarização afirma que o desenvolvimento não surge em todo o espaço econômico ou lugares ao mesmo tempo. Ele propaga-se por vias e com impactos diferenciados no conjunto da economia ao longo do tempo. O pólo é caracterizado como o centro econômico da região e ele cria fluxos da região para o centro e refluxos do centro para a região. Nesse contexto, a região deve ser entendida como área de influência de um pólo. Essa influência se dá nas relações comerciais, administrativas, sociais, demográficas e políticas (PERROUX, 1977).

Para Santos (2003) a polarização se dá através dos serviços urbanos que a cidade é capaz de oferecer. As transformações ocorridas no meio urbano e no rural devido ao crescimento da produção e da acumulação de capital reduzem a oferta de trabalho e expulsam mão-de-obra. Dessa forma, a urbanização disponibiliza serviços diferenciados e diversificados, e torna-se atrativa para novos investimentos, para a população e para as atividades que necessitam desse "meio" como instrumento de rentabilização do capital.

Portanto, verifica-se que a localização das atividades econômicas define situações de sucesso ou atraso econômico da região, por exemplo, possibilitam que 
determinados espaços sejam classificados como pólos de desenvolvimento ou crescimento econômico, que será discutido na próxima seção.

\section{$\underline{\text { Teorias de desenvolvimento regional: aglomeraç̃ó e polarização }}$}

A abordagem da relação existente entre economia e espaço está presente nos primórdios da economia urbana e da geografia econômica. Lima (2014) sintetiza a evolução dos grupos teóricos que passaram a estudar esses aspectos e sinaliza a emergência de três escolas: teorias neoclássicas de localização; teorias de desenvolvimento regional e teorias do desenvolvimento econômico endógeno. Ainda de acordo com a autora:

Os diferentes estágios de desenvolvimento alcançados mediante o surgimento de atividades econômicas em um determinado espaço contribuiu para as discussões que possibilitassem entender como ocorre esse processo e os fatores chaves para explicar essas desigualdades regionais. Assim, o conceito de desenvolvimento regional vincula essa abordagem territorial e possibilita relacionar a economia e o espaço (LIMA, 2014, p. 40)

Inicialmente a discussão concentrava-se na explicação dos fatores que condicionaram a localização das atividades produtivas em um dado espaço. Nesse primeiro momento verificou-se a predominância de estudos de geógrafos como Christaller e Losch e, logo após a Segunda Guerra Mundial, surgiram as contribuições de economistas como Isard, Myrdal e Perroux (MARINI; SILVA, 2012).

Kon (1999) elenca vários fatores que justificam a escolha da localização da indústria, os quais são: custos e eficiência dos transportes; áreas de mercado; disponibilidade e custos de mão-de-obra; custo da terra; disponibilidade de energia; suprimento de matérias-primas; disponibilidade de água; dispositivos fiscais e financeiros; economias de aglomeração.

Identificam-se vários argumentos que pretendem justificar a especialização e concentração das atividades econômicas. As vantagens comparativas, a presença das economias de escala; e economias externas ou externalidades marshallianas são alguns dos grupos teóricos baseados na explicação locacional das atividades econômicas. A importância da aglomeração produtiva emerge das vantagens obtidas pelas empresas, principalmente as pequenas e médias, com a aglomeração industrial (externalidades) (MARSHALL, 1988).

Assim, há um "hiato" crescente entre os diversos espaços, pois o crescimento de uma região resultaria na geração de externalidades positivas ou negativas sobre as demais regiões. Se as externalidades forem negativas, elas intensificam as disparidades regionais e a concentração. Dessa maneira, tal processo aglomerativo fortalece a polarização. Ao contrário, as externalidades positivas estimulam a dispersão das atividades. Tais externalidades estão ligadas ao perfil dos fatores de produção.

Analisando a existência de mobilidade dos fatores de produção capital e trabalho, externalidades negativas ocorrem por tais elementos: intercâmbio comercial, a deterioração das relações de troca; movimento do capital, falta de infraestrutura adequada, população com baixo grau de escolaridade e outros gargalos. Frente a deficiências nesses elementos, o capital migra para as regiões onde estas 
necessidades são atendidas; e, as migrações, pois as regiões com alto índice de crescimento geram um processo migratório (ALONSO, 1986).

As ferramentas de neutralização das externalidades negativas sob as regiões periféricas, o que é proposto é a criação de pontes de interligação entre as atividades dos pólos de crescimento e a dos pólos secundários e seu interior, de forma a integrar as regiões e suas atividades produtivas (SOUZA, 1993).

Dessa forma, há o entendimento de que a proximidade regional e a especialização produtiva contribuem substancialmente para as ações conjuntas resultando em uma melhor eficiência coletiva. Foi visto também que a existência das desigualdades regionais, problema inerente à região, evidencia a necessidade de políticas públicas que possam minimizar as consequências para as mais diversas regiões, e tais políticas devem se fundamentar nas particularidades e nas demandas de cada espaço.

\section{PROCEDIMENTOS METODOLÓGICOS}

A área de estudo desta pesquisa são as mesorregiões geográficas do Paraná, definidas pelo Instituto Brasileiro de Geografia e Estatística (IBGE). As mesorregiões geográficas paranaenses se dividem conforme a Figura 1.

Figura 1 - Mesorregiões Geográficas do Paraná - 2013
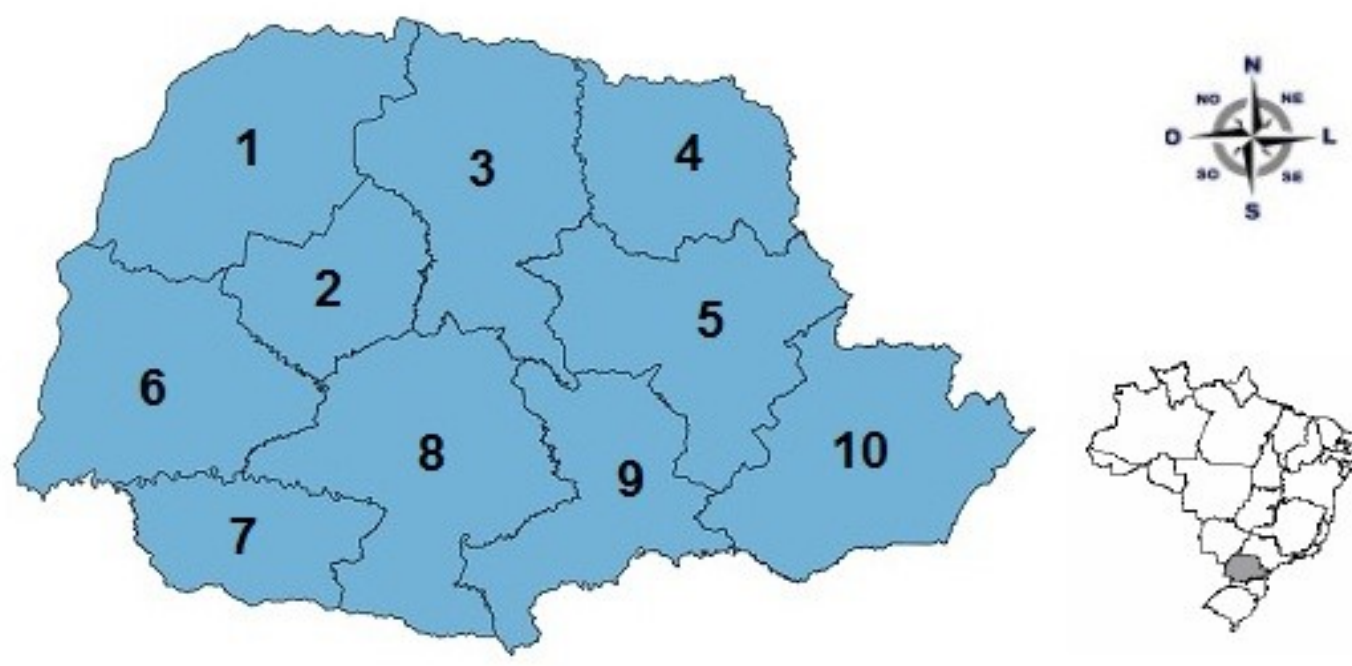

Mesorregiōes Geográficas:

1 - Noroeste Paranaense

2 - Centro-Ocidental Paranaense

3 - Norte Central Paranaense

4 - Norte Pioneiro Paranaense

5 - Centro-Oriental Paranaense
6 - Oeste Paranaense

7 - Sudoeste Paranaense

8 - Centro-Sul Paranaense

9 - Sudeste Paranaense

10 - Metropolitana de Curitiba

Fonte: Elaboração própria.

Para alcançar o objetivo principal desse estudo foram utilizadas as medidas de localização para analisar a aglomeração das atividades econômicas entre as mesorregiões. As medidas de localização são medidas de natureza setorial e se preocupam com a localização dos setores econômicos entre as regiões. O principal 
objetivo é identificar padrões de concentração ou dispersão espacial do emprego (ALVES, 2012). Os resultados serão apresentados por meio de figuras que permitem constatar o perfil locacional das mesorregiões paranaenses, e, consequentemente, o perfil da aglomeração.

Optou-se por utilizar como variável de análise o emprego formal ${ }^{4}$ por ramos de atividades da economia, coletadas na Relação Anual de Informações Sociais (RAIS), do Ministério do Trabalho e do Emprego (MTE). A escolha dessa variável se deu porque se pressupõe que o emprego reflete a geração e distribuição de renda regional, o que estimula o consumo e a dinâmica das regiões (ALVES, 2012).

O período de análise compreende os anos de 2002 e 2011. Os ramos de atividades industriais em indústrias dinâmicas, tradicionais e não tradicionais foram agregados da seguinte forma:

- Indústrias Tradicionais: Indústria de Produtos Alimentícios, de Bebida e Álcool Etílico, Indústria da Madeira e do Mobiliário, Indústria Têxtil, do Vestuário e Artefatos de Tecidos e Indústria de Calçados;

- Indústrias Não-Tradicionais: Indústria da Borracha, Fumo, Couros e Peles.

- Indústria Dinâmica: Indústria Extrativa Mineral, Indústria de Produtos Minerais não Metálicos, Indústria Metalúrgica, Indústria Mecânica, Indústria de Materiais Elétricos e de Comunicação, Indústria de Materiais de Transporte, Indústria do Papel, Papelão, Editorial e Gráfica, Indústria Química, Produtos Farmacêuticos, Veterinários, Perfumaria, Sabões, Velas e Matérias Plásticas.

Além das indústrias tradicionais, indústrias não-tradicionais e indústrias dinâmicas, os demais setores analisados serão: Construção Civil; Comércio (varejista e atacadista); Transporte e Comunicações; Ensino; Administração Pública; Agricultura e Outras Atividades Terciárias ${ }^{5}$.

\section{Indicadores de análise regional}

Para a estimativa dos indicadores de análise regional procedeu-se à construção da matriz de informações: organizaram-se as informações em uma matriz que relacionou a distribuição setorial-espacial da variável base. Com as matrizes construídas, o cálculo de diferentes tipos de medidas permitiu "descrever padrões de comportamento dos setores produtivos no espaço econômico, assim como padrões diferenciais de estruturas produtivas entre as várias regiões" (HADDAD, 1989, p. 227).

\section{A matriz de Informações Espaciais}

As informações foram organizadas em uma matriz, na qual cada linha mostra a distribuição total do emprego formal de uma dada atividade entre as diferentes mesorregiões, e cada coluna mostra como o emprego formal total de uma dada mesorregião se distribui entre as diferentes atividades. Para a construção da matriz espacial define-se:

$E_{i j}=$ emprego formal na atividade $i$ da mesorregião $j$;

\footnotetext{
${ }^{4} \mathrm{O}$ emprego formal se caracteriza pelos trabalhadores que exercem atividade remunerada com carteira de trabalho assinada.

${ }^{5} \mathrm{O}$ setor de Outras Atividades agrega as seguintes atividades: Instituições Financeiras; Serviços de administração técnica profissional, Serviços de Alojamento e Comunicação; Serviços Médicos, Odontológicos e Veterinários e Serviços de Utilidade Pública.
} 
$E_{. j}=\sum_{i} E_{i j}=$ emprego formal em todas as atividades da mesorregião $j$;

$E_{i .}=\sum_{j} E_{i j}=$ emprego formal na atividade $i$ de todas as mesorregiões;

$E . .=\sum_{i} \sum_{j} E_{i j}=$ emprego formal em todas as atividades de todas as mesorregiões.

Assim, pode-se apresentar a matriz de informação da seguinte forma:

Figura 2 - Matriz de informação

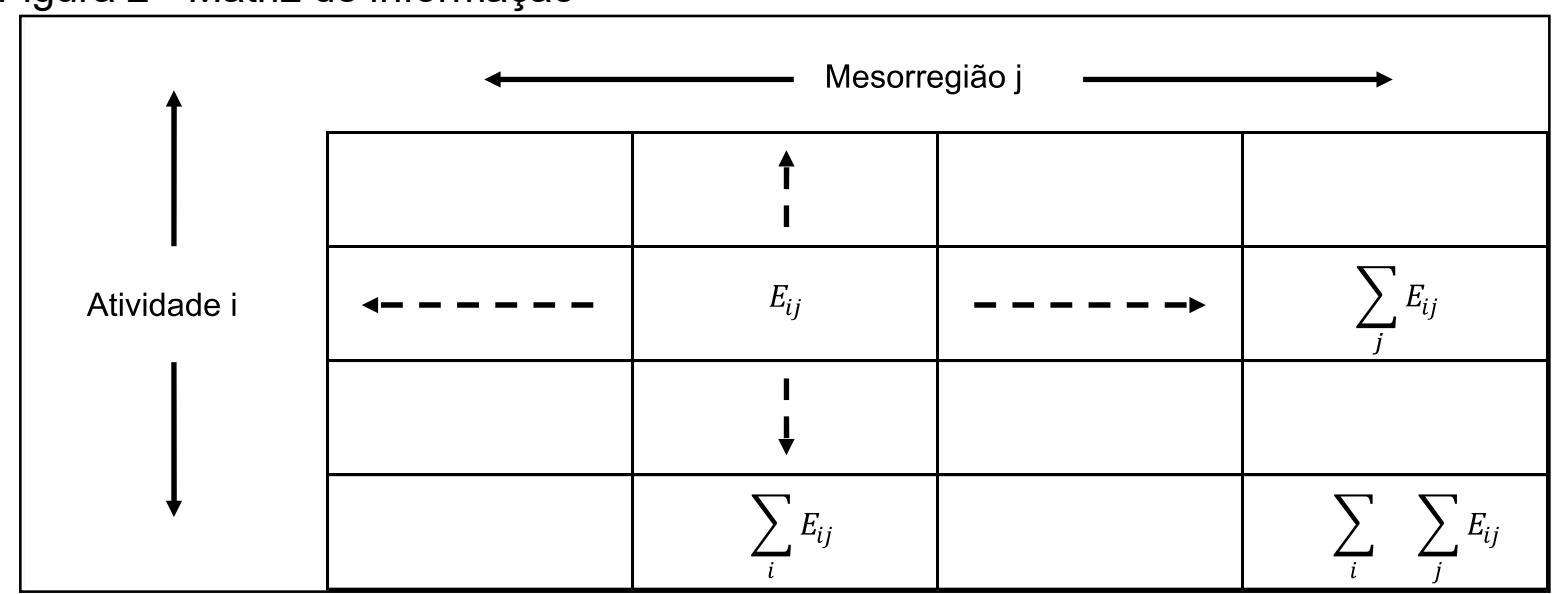

Fonte: Adaptado de Haddad (1989, p. 226).

A partir da matriz espacial, são derivadas outras duas que mostram, em termos percentuais, a distribuição do emprego em cada mesorregião por atividade, e a distribuição do emprego de cada atividade entre as mesorregiões paranaenses:

$$
\begin{gathered}
i^{e} j=\frac{E_{i j}}{\sum_{i} E i j} \\
j^{e} i=\frac{E_{i j}}{\sum_{j} E_{i j}}
\end{gathered}
$$

sendo: $\sum_{i} i^{e} j=1,00 ; \sum_{j} j^{e} i=1,00 ; i^{e} .=\sum_{j} i^{e} j ;$ e $j^{e} .=\sum_{i} j^{e} i$.

As medidas regionais concentram-se na análise da estrutura produtiva das atividades produtivas de cada mesorregião, identificando a distribuição do emprego formal e a especialização das economias regionais, no período de 2002 a 2011.

\section{Quociente Locacional}

O quociente locacional do ramo de atividade $i$ na região $j$ é definido como:

$$
Q L_{i j}=\frac{E_{i j} / E_{i .}}{E_{. j} / E_{. .}}
$$


O quociente locacional (QL) compara a participação percentual de uma região, em um dos ramos de atividade, com a participação percentual da mesma mesorregião, no total do emprego formal. Se o valor do quociente for maior que a unidade (1), isto significa que a mesorregião é, relativamente, mais importante no contexto estadual, em termos do ramo de atividade, do que em termos gerais de todos os ramos de atividades.

\section{Coeficiente de Redistribuição}

O Coeficiente de Redistribuição (CR) relaciona a distribuição percentual do emprego formal de um mesmo ramo de atividade em dois períodos de tempo, com o objetivo de examinar se está prevalecendo para a atividade algum padrão de concentração ou dispersão espacial ao longo do tempo.

O CR da atividade $i$ entre os períodos 0 (zero) e 1 (um) é definido como:

$$
C R_{i}=\frac{\sum_{j}\left(\left|j^{t_{1}}{ }^{t_{0}}-j^{e i}\right|\right)}{2^{e i}}
$$

O seu valor oscila entre os limites 0 (zero) e 1 (um), ou seja, se o coeficiente for próximo de 0 (de 1), entre os dois períodos de análise, não terão (terão) ocorrido mudanças significativas no padrão espacial de localização do setor.

\section{RESULTADOS E DISCUSSÕES}

Com vistas a analisar a distribuição espacial das diversas atividades produtivas nas mesorregiões paranaenses segundo o emprego formal, a seguir foram elencadas as figuras temáticas com os resultados da pesquisa.

Na Figura 3 é apresentado o perfil de localização do Quociente Locacional (QL) do emprego formal das atividades Administração Pública e Agricultura no estado do Paraná. No tocante a atividade de Administração Pública, verifica-se uma concentração do emprego formal de 2002 para 2011, ou seja, em 2002 seis mesorregiões apresentaram QL acima de 1. Já em 2011, a concentração da atividade diminuiu para cinco mesorregiões. Destaca-se também que em 2002 as mesorregiões com maior concentração de emprego formal na atividade de Administração Pública se localizavam nas regiões Noroeste e Sudeste, formando um corredor, já em 2011 essa configuração se altera mostrando uma localização mais próxima a mesorregião Metropolitana de Curitiba.

Como mostra Kureski e Delgado (2010), o crescimento da atividade de administração pública está relacionado com o crescimento populacional e o número de funcionários públicos, bem como pela ampliação dos gastos públicos. Ainda de acordo com os autores, setorialmente essa atividade era a segunda atividade com maior participação do setor de serviços, depois do comércio. 
Figura 3 - Perfil de Localização (QL) do Emprego Formal das atividades Administração Pública e Agricultura, segundo as mesorregiões geográficas do Paraná em 2002 e 2011

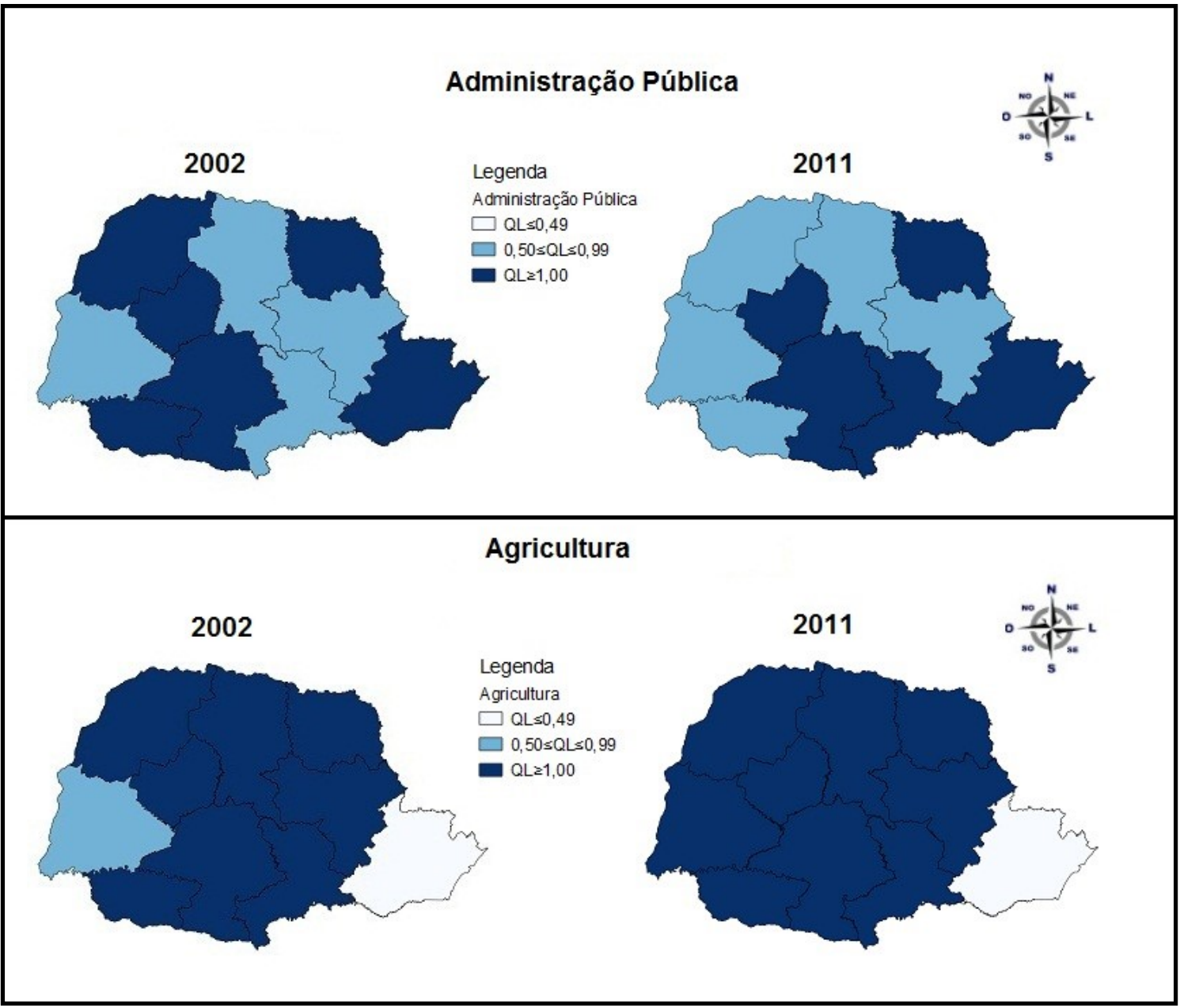

Fonte: Resultados da pesquisa a partir da RAIS, 2013.

O setor da Agricultura, assim como a Indústria Tradicional, é a atividade mais dispersa do estado do Paraná dentre as demais atividades analisadas. Verificou-se que essas atividades melhoraram sua distribuição de 2002 para 2011, pois a mesorregião Oeste que apresentava menor QL passa a apresentar QL superior à unidade em 2011. Assim, somente a mesorregião Metropolitana de Curitiba apresentou baixa especialização nessa atividade, isso se justifica por ser fortemente especializada em outras atividades como: Administração Pública, Construção Civil, Outras Atividades Terciárias, Indústria Dinâmica e Transporte e Comunicação.

Na Figura 4 apresenta-se o perfil de localização do QL do emprego formal das atividades Ensino, Construção Civil e Outras Atividades Terciárias no estado do Paraná. 
Figura 4 - Perfil de Localização (QL) do Emprego Formal das atividades de Ensino, Construção Civil e Outras Atividades Terciárias, segundo as mesorregiões geográficas do Paraná em 2002 e 2011

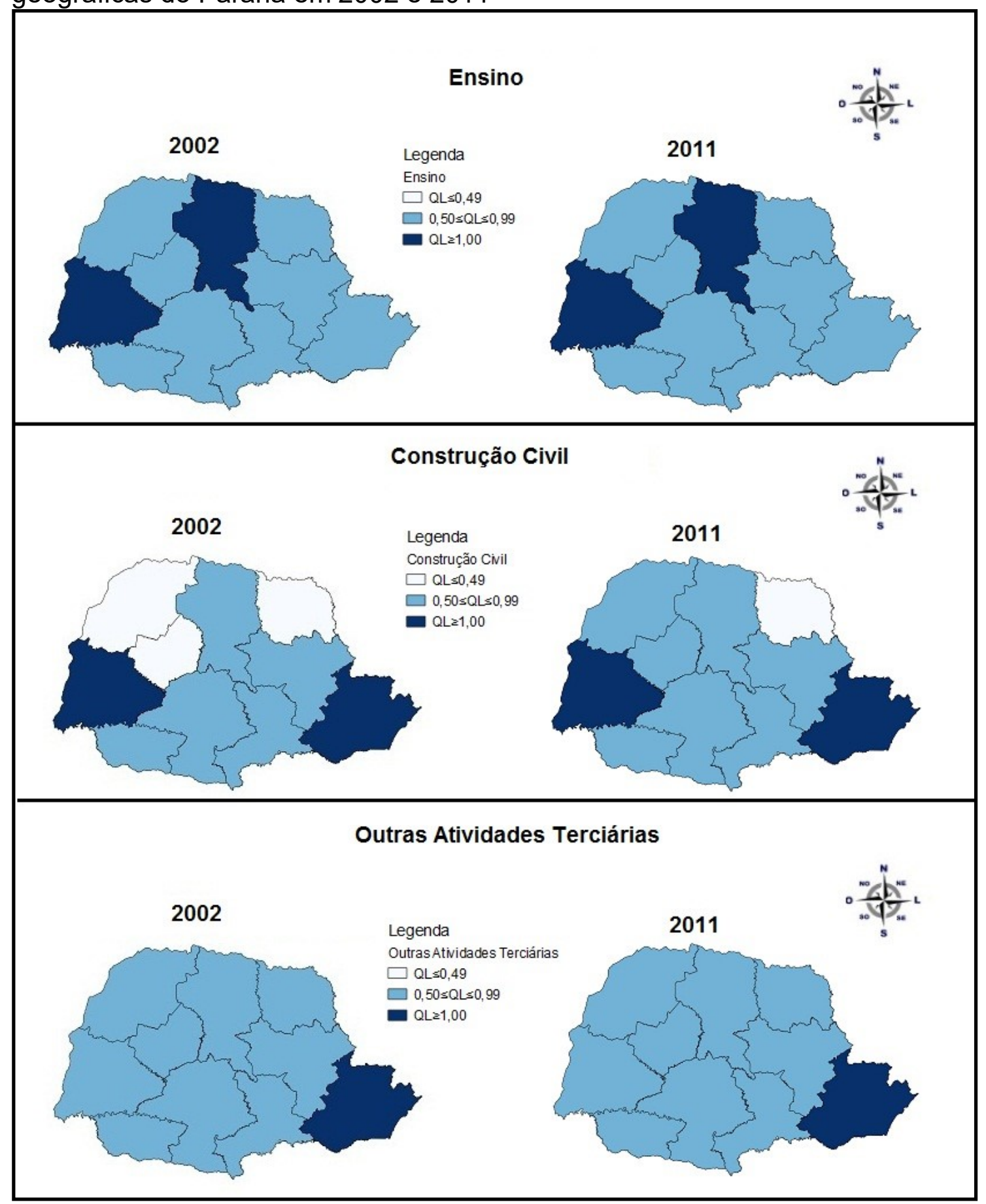

Fonte: Resultados da pesquisa a partir da RAIS, 2013.

A atividade de Ensino apresentou uma concentração elevada, somente as mesorregiões do Norte Central e Oeste apresentaram QL maior que a unidade. Além disso o desempenho espacial foi semelhante nos dois anos de estudo (2002 e 2011). O desempenho da atividade de educação no estado relaciona-se à ampliação das políticas sociais destinadas e também pelo aumento da atuação da rede privada nesse setor, que corroboram a elevada representatividade setorial no estado. 
A Construção Civil, o Ensino e Outras Atividades Terciárias são atividades bastante concentradas, com apenas duas mesorregiões com QL acima da unidade. $\mathrm{Na}$ atividade Construção Civil somente as mesorregiões Metropolitana de Curitiba e Oeste Paranaense, no entanto, verifica-se também o aumento da especialização da mesorregião Noroeste e Centro-Oriental Paranaense de 2002 para 2011. Isso é explicado pelo aumento da urbanização dessas mesorregiões, a mesorregião Noroeste teve o maior aumento no grau de urbanização dentre as mesorregiões, em 2000 era 77,27\% urbanizada, já em 2010 era 83,40\%. A mesorregião Centro-Oriental não se urbanizou tanto no período, mas seu grau de urbanização aumentou $3,49 \%$ (IPARDES, 2013).

As Outras Atividades Terciárias se mostraram como as mais concentradas dentre as atividades analisadas. Isso porque somente a mesorregião Metropolitana de Curitiba apresentou QL maior que 1. A presença da capital Curitiba nessa mesorregião pode justificar a concentração de empregos formais em instituições financeiras, serviços médicos, alojamento e comunicação e serviços de utilidade pública que tendem a se concentrar na capital do estado.

A Indústria Tradicional é a atividade que mais emprega mão-de-obra de todas as demais atividades industriais do estado do Paraná. É também a atividade que se apresenta como sendo a mais dispersa do estado, abrangendo todas as mesorregiões paranaenses, exceto a mesorregião Metropolitana de Curitiba, que concentra mais na atividade da Indústria Dinâmica (Figura 5).

Já na atividade da Indústria Não-Tradicional merecem destaque no ano de 2002 apenas três mesorregiões: Noroeste, Norte Central e Metropolitana de Curitiba. Em 2011 as mesorregiões Noroeste e Metropolitana de Curitiba, diminuem sua especialização nessa atividade, enquanto a mesorregião Centro-Oriental passa a apresentar maior especialização.

O perfil industrial do Paraná revela uma elevada disparidade no que concerne a localização da atividade nas mesorregiões. Estudo realizado por Bravin, Góes e Bravin (2015) ressalta que a distribuição desigual do setor resulta na concentração da indústria tradicional nos municípios que não sejam da mesorregião Metropolitana de Curitiba. Na figura 5 ratifica-se esse padrão de concentração de segmentos tradicionais em todas as mesorregiões, exceto a Metropolitana de Curitiba.

De acordo com Gualda (2006), cabe destaque para os cinco principais segmentos industriais do interior do estado, que são: vestuário e acessórios; madeireiro; alimentícios e bebidas; fabricação de móveis; e fabricação de produtos minerais não metálicos. Com relação aos fatores explicativos, os autores Bravin, Góes e Bravin (2015, p. 11) ressaltam que:

Ao analisarmos as principais indústrias distribuídas no interior do Paraná, percebemos que a maioria delas se apoiam em segmentos tradicionais, ligados a agroindústria, devido a fatores históricos, físicos e de incentivos públicos ou externos a essas atividades, contrapondo-se a região metropolitana de Curitiba, onde também estão inseridas indústrias tradicionais, no entanto, predominam nessa região aglomerações industriais de alta tecnologia. 
Figura 5 - Perfil de Localização (QL) do Emprego Formal das atividades Indústria Tradicional, Indústria Não-Tradicional e Indústria Dinâmica, segundo as mesorregiões geográficas do Paraná em 2002 e 2011

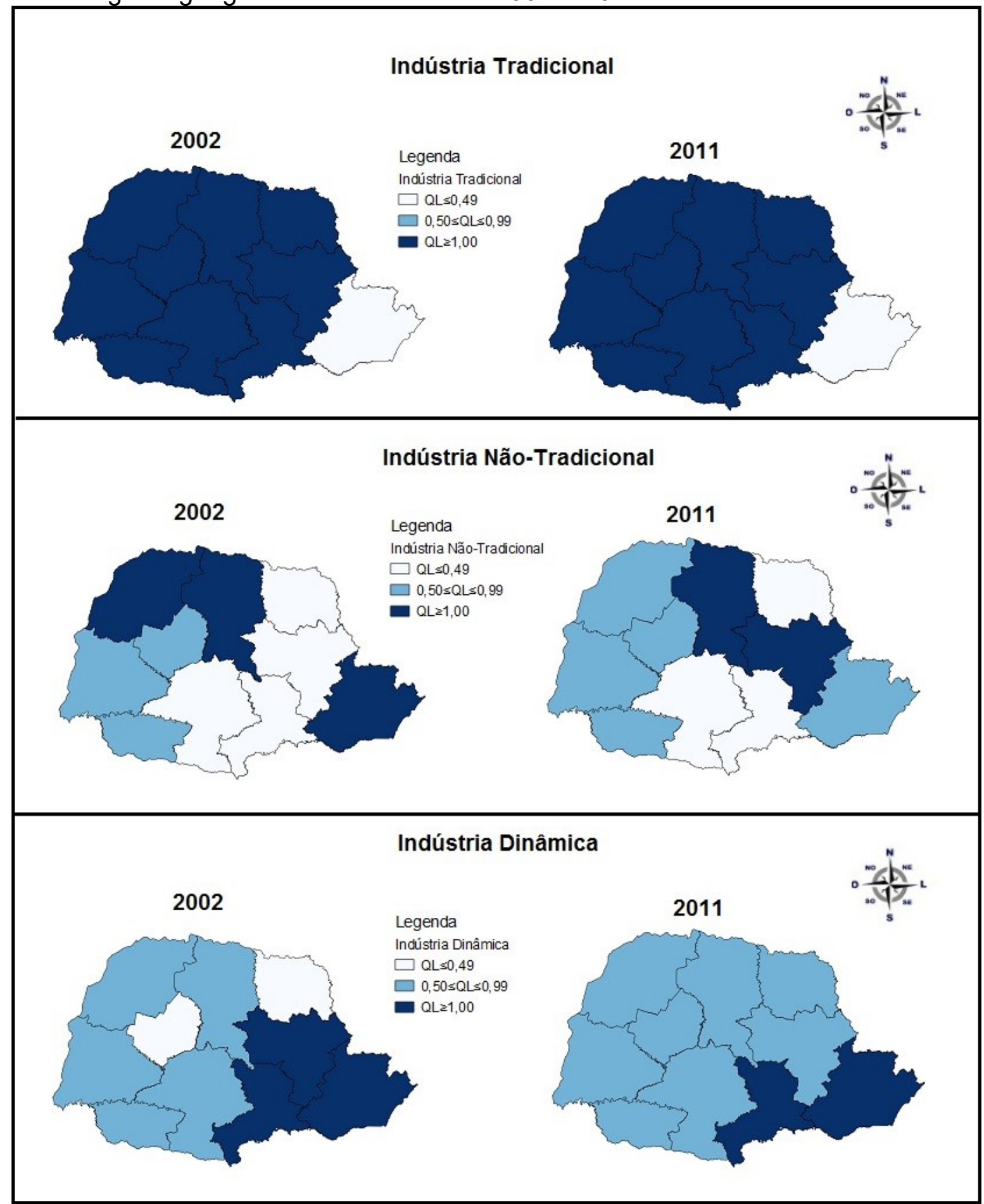

Fonte: Resultados da pesquisa a partir da RAIS, 2013.

A Indústria Dinâmica é altamente concentrada em duas mesorregiões: Metropolitana de Curitiba e Sudeste Paranaense. A proximidade espacial destas duas mesorregiões corrobora um padrão locacional altamente seletivo da Indústria Dinâmica em torno dessa área. O setor corresponde a uma diversidade de atividades 
industriais, de elevado valor agregado com destaque para o pólo automotivo da mesorregião Metropolitana de Curitiba.

Deve-se ressaltar ainda que se alterou o comportamento das mesorregiões Centro-Ocidental e Norte Pioneiro que melhoraram a distribuição do emprego formal nessa atividade, enquanto a mesorregião Centro-Oriental piorou sua distribuição, apresentando menor QL em 2011. Na Figura 6 apresenta-se o perfil de localização do QL do emprego formal das atividades do Comércio e Transporte e Comunicações no estado do Paraná.

Figura 6 - Perfil de Localização (QL) do Emprego Formal das atividades Comércio e Transporte e Comunicações, segundo as mesorregiões geográficas do Paraná em 2002 e 2011

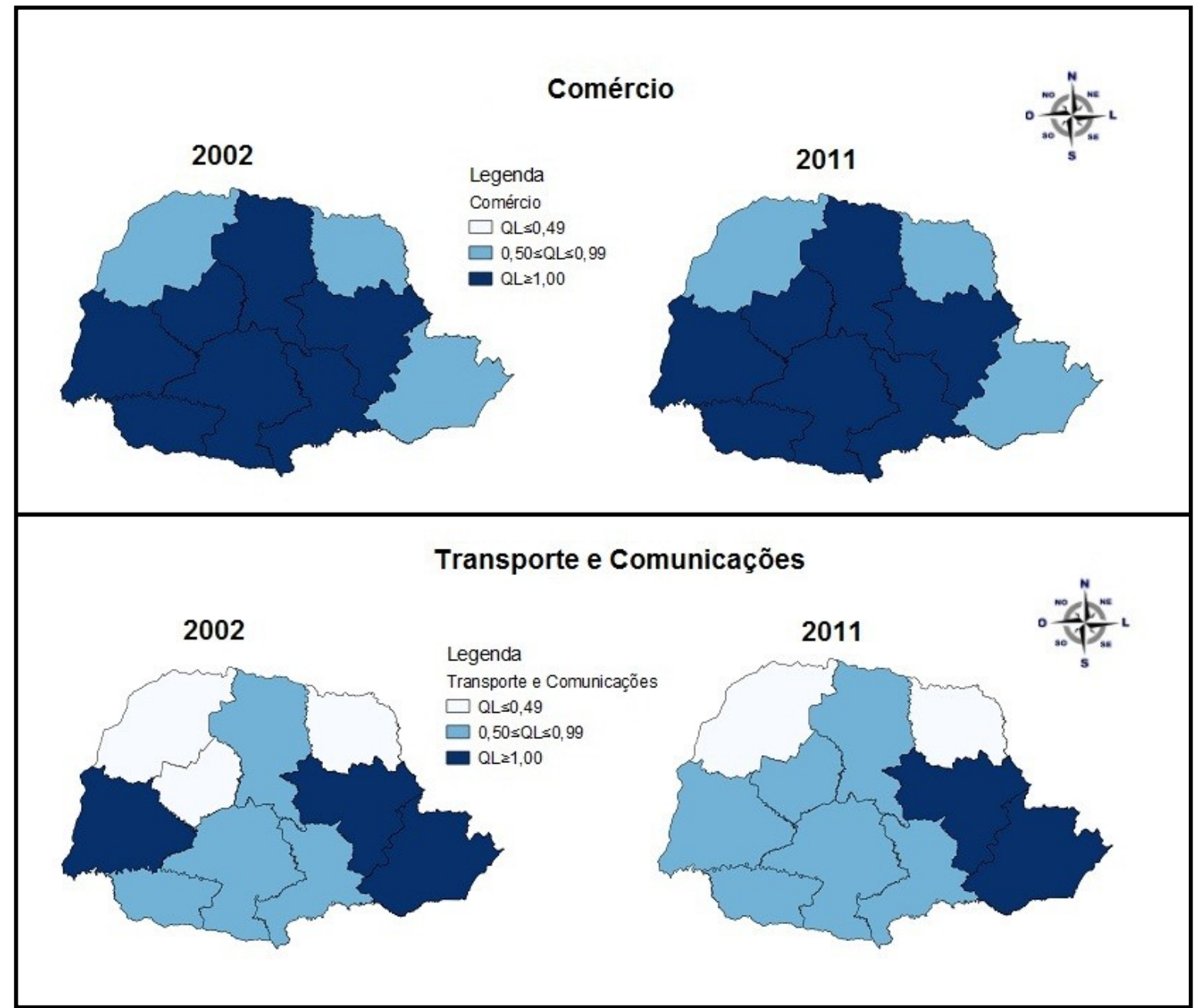

Fonte: Resultados da pesquisa a partir da RAIS, 2013.

O setor de Comércio apresentou um padrão espacial igual em 2002 e 2011, sendo uma das atividades mais dispersas do estado, com sete mesorregiões apresentando QL acima da unidade, somente as mesorregiões Noroeste, Norte Pioneiro e Metropolitana de Curitiba apresentaram média especialização.

A atividade de Transportes e Comunicações permaneceu concentrada e podemos dizer que houve um aumento da concentração de 2002 para 2011. As mesorregiões Metropolitana de Curitiba e Centro-Oriental Paranaense foram as únicas a apresentar QL maior que a unidade em 2011. A mesorregião Oeste Paranaense teve uma piora na distribuição do emprego formal enquanto a 
mesorregião Centro Ocidental apresentou uma melhora na sua distribuição do emprego formal.

Verifica-se pelo coeficiente de redistribuição (Quadro 1) que a Agricultura foi a atividade que mais se redistribuiu no período 2002 a 2011, ou seja, essa atividade se difundiu no período analisado.

Quadro 1 - Classificação dos ramos de atividades das mesorregiões paranaenses segundo os coeficientes de redistribuição em relação ao Paraná - 2002/2011

\begin{tabular}{|l|l|l|}
\hline Grupos & CR & Ramo de Atividade \\
\hline \multirow{2}{*}{ I Redistribuição não } & 0,0171 & 0,0184 \\
Significativa & 0,0215 & Administração Pública \\
& 0,0222 & Comércio \\
\hline \multirow{2}{*}{ II Redistribuição Média } & 0,0430 & Outras Atividades Terciárias \\
& 0,0525 & Transporte e Comunicações \\
\hline \multirow{2}{*}{ Redistribuição } & 0,0622 & Construção Civil \\
Significativa & 0,0833 & Indústria Dinâmica \\
\hline
\end{tabular}

Fonte: Resultados da Pesquisa.

Vale salientar que os ramos de atividades da Indústria Não-Tradicional; Indústria Tradicional e Agricultura foram os que apresentaram os maiores coeficientes de redistribuição. Esses dados mostram que essas três atividades se difundiram entre as mesorregiões. Já as atividades de Administração Pública, Comércio, Outras Atividades Terciárias e Transporte e Comunicações foram as atividades que menos se redistribuíram no espaço.

\section{CONSIDERAÇÕES FINAIS}

Este trabalho teve como objetivo principal analisar a concentração espacial das atividades econômicas, Administração Pública, Agricultura, Ensino, Construção Civil, Outras Atividades Terciárias, Indústria Tradicional, Indústria Não-Tradicional, Indústria Dinâmica, Comércio, Transportes e Comunicações, entre as mesorregiões paranaenses nos anos de 2002 e 2011. Utilizou-se o Quociente Locacional e o Coeficiente de Redistribuição para indicar as aglomerações espaciais no que concerne ao comportamento do emprego formal nas mesorregiões.

Os resultados mostraram que a maior parte das mesorregiões do estado do Paraná ainda possuem suas economias voltadas para a atividade da Agricultura. Fato justificado pela grande produção agrícola do estado do Paraná, o qual ocupa a segunda posição nacional na produção de grãos e primeiras colocações na atividade criatória de aves, suínos e bovinos.

A expressiva concentração econômica na atividade da Agricultura evidenciada através dos cálculos do Quociente Locacional (QL), demonstrou que apenas um pequeno grupo de mesorregiões apresentou uma localização forte do emprego formal na Indústria Dinâmica (Centro-Oriental, Sudeste e Metropolitana de Curitiba) e Não-Tradicional (Noroeste, Norte Central, Centro-Oriental), sendo que a 
Indústria Tradicional é bem mais dispersa no Paraná, graças principalmente as empresas cooperativas que atuam no estado.

As atividades de Transporte e Comunicação, Construção Civil e Outras Atividades Terciárias foram as que se mostraram mais concentradas no estado do Paraná. Somente as mesorregiões Oeste, Centro-Oriental e Metropolitana de Curitiba é que apresentaram QL maior que a unidade para essas atividades econômicas.

As mesorregiões, Centro-Oriental, Oeste, Metropolitana de Curitiba, Norte Central e Sudeste, são as mesorregiões que possuem suas estruturas produtivas mais diversificadas dentre as demais mesorregiões do estado do Paraná, com destaque para as atividades da Indústria (Dinâmica e Tradicional) e setores relacionados ao setor terciário da economia (prestação de serviços) como Comércio, Administração Pública, Ensino, Transporte e Telecomunicações, Construção Civil e Outras Atividades Terciárias.

Pode-se concluir que o setor da Indústria Tradicional é a principal atividade responsável pela absorção de mão-de-obra formal em todas as mesorregiões exceto a mesorregião Metropolitana de Curitiba.

Diante desse contexto, o futuro econômico do estado do Paraná estará muito atrelado a sua capacidade de dinamizar e diversificar as suas estruturas produtivas, principalmente das mesorregiões com menor dinamismo. Portanto, a heterogeneidade locacional das atividades econômicos no estado do Paraná, faz emergir a necessidade de políticas que contemplem as mesorregiões com o menor dinamismo, ou seja, as políticas públicas adotadas devem estar relacionadas com as especificidades de cada mesorregião.

\section{REFERÊNCIAS}

ALONSO, J. A. F. Evolução das Desigualdades Inter- Regionais de Renda Interna no Rio Grande do Sul 1939 -1970. Porto Alegre: Fundação de Economia e Estatística, $\quad 2^{\circ} \quad$ impressão, 1986.1 Disponível em: <http://searchworks.stanford.edu/view/1557439>. Acesso em: 06 jun. 2013.

ALVES, L. R. Indicadores de Localização, especialização e estruturação regional. In.: PIACENTI, C. A.; FERRERA DE LIMA, J. (Orgs.) Análise Regional: Metodologias e Indicadores. Curitiba, PR: Camões, 2012.

BRAVIM, N. J. R.; GÓES, S. L. V.; BRAVIN, S. M. R.; A FORMAÇÃO INDUSTRIAL NO PARANÁ: do desenvolvimento e formação de aglomerados a distribuição desigual no espaço. In OBSERVATORIUM: Revista Eletrônica de Geografia, v.7, n.18, p. 4866 , set. 2015

FERRERA DE LIMA, J.; EBERHARDT, P. H. de C. Mesorregião Grande Fronteira do Mercosul: perfil locacional do desenvolvimento regional. Revista Redes, Santa Cruz do Sul, v. 15, n. 2, p. 134 - 151, maio/ago. 2010.

GUALDA, Neio Lúcio Peres, et. al. Identificação das Aglomerações Industriais no Estado do Paraná - Um estudo explanatório. Revista Brasileira de Economia de Empresas, v. 6, p. 47-63, 2006. 
INSTITUTO DE PESQUISA ECONÔMICA APLICADA - IPEA. Caracterização e tendências da rede urbana do Brasil: desenvolvimento regional e estruturação da rede urbana. Brasília: IPEA, v.3, 2001. 127 p.

INSTITUTO PARANAENSE DE DESENVOLVIMENTO ECONÔMICO E SOCIAL IPARDES. Base de Dados do Estado - BDEweb. Disponível em: <http://www.ipardes.gov.br/imp/index.php>. Acesso em: 07 out. 2013.

KON, A. Economia de serviços: Teoria e evolução no Brasil. Rio de Janeiro: Elsevier, 2004LOPES, A. S. O espaço econômico. In: COSTA, J. S. (coord.). Compêndio de economia regional. Coimbra: APDR, 2002.

KURESKI, R.; DELGADO, P. R.; A importância do setor de serviços no estado do Paraná. Revista Paranaense de Desenvolvimento, Curitiba, n. 118, p. 139 - 158, 2010.

LIMA, É. P. C. de; Desenvolvimento regional: um debate sobre as políticas industriais no Rio Grande do Norte. Dissertação de Mestrado do Programa de Estudos Urbanos e Regionais, UFRN, 2014.

MARINI, M. J. ; SILVA, C. L. . Desenvolvimento Regional e Arranjos Produtivos Locais: uma abordagem sob a ótica interdisciplinar. Revista Brasileira de Gestão e Desenvolvimento Regional, v. 8, p. 107-129, 2012

MARSHALL, A. Princípios de economia: tratado introdutório. $3^{a}$ ed., v. 1-2, São Paulo: Nova Cultura, 1988.

MINISTÉRIO DO TRABALHO E EMPREGO - MTE. Dados da RAIS/CAGED. Disponível em: <http://sgt.caged.gov.br/>. Acesso em: 12 set. 2013.

PERREIRA, S. M.; FERRERA DE LIMA, J. Atratividade e Polarização nas Mesorregiões do Estado do Paraná. Revista Ciências Sociais em Perspectiva, v. 7, $\mathrm{n}^{\circ} \quad 13,2008.2$ Disponível em: revista.unioeste.br/index.php/ccsaemperspectiva/issue/view/264/showToc>. Acesso em: 07 jun. 2013.

PERROUX, F. O Conceito de pólo de crescimento. In.: SCHWARTZMAN, J. (Org.). Economia Regional: textos escolhidos. CEDEPLAR/CETREDE-MINTER, 1977.

PIFFER, M. Apontamentos sobre a base econômica da região Oeste do Paraná. In: CASSIMIRO FILHO, F. \& SHIKIDA, P. F. A. (Orgs.) Agronegócio e Desenvolvimento regional. p. 57-84. EDUNIOESTE: Cascavel, 1999.

POLĖSE, M. Economia urbana e regional: lógica espacial das transformações econômicas. Coimbra; APDR, 1998.

SANTOS, M. Economia espacial. 2. ed. São Paulo: Edusp, 2003. 
SOUZA, N. J. Conceito e aplicação da teoria da base econômica. Revista Perspectiva Econômica. São Leopoldo, v. X, n. 25, p. 117-130, março 1980.

Desenvolvimento Polarizado e Desequilíbrios Regionais no Brasil. IN: Análise Econômica, ano 11, n. 19 p. 29-59, mar.1993 